\title{
Non-small Cell Lung Cancer (NSCLC) in Octogenarians in Clinical Practice
}

\author{
HIRSH KOYI ${ }^{1,2,3}$, GUNNAR HILLERDAL ${ }^{1,4}$, KARL-GUSTAV KÖLBECK $^{4}$, \\ DANIEL BRODIN ${ }^{4}$, PER LIV $^{3}$ and EVA BRANDÉN ${ }^{1,2,3}$ \\ ${ }^{1}$ Department of Respiratory Medicine, Gävle Hospital, Gävle, Sweden; \\ ${ }^{2}$ Karolinska Institutet, Stockholm, Sweden; \\ ${ }^{3}$ Centre for Research and Development, Uppsala University/County Council of Gävleborg, Gävle, Sweden; \\ ${ }^{4}$ Department of Respiratory Medicine and Allergy, Karolinska University Hospital, Solna, Stockholm, Sweden
}

\begin{abstract}
Background/Aim: Globally, an increasing proportion of cancer patients are aged $>65$ years and many are aged $>70$ years. Treatment of the elderly with lung cancer has, therefore, become an important issue. We performed a retrospective study of our patients to demonstrate how octogenarians with non-small cell lung cancer (NSCLC) are treated in real-life clinical practice. Patients and Methods: This was a retrospective observational study of all elderly $(\geq 80$ years) patients with NSCLC referred to the Department of Respiratory Medicine and Allergy, Karolinska Hospital, Sweden, 2003-2010, and followed until June, 2016. Results: In total, 452 patients, 216 (47.8\%) men and 236 (52.2\%) women, were included. The mean and median age was 83 years; 28 $(6.2 \%)$ were aged 90 years or more. Current or former smokers constituted $91.1 \%$, with men having smoked more $(p<0.001)$. There was no difference in performance status (PS) between genders with PS 0-1 in 45.4\%, PS 2 in 25.6\% and PS3-4 in $29 \%$. About a third each was diagnosed in stages 1-II, III and IV. Adenocarcinoma was most common (45.6\%), $18.1 \%$ had squamous cell carcinoma, while histological diagnosis was unavailable in $23.2 \%$. Best supportive care (BSC) was given only to 209 patients (46.2\%). Potentially curative therapy was administered to $16.5 \%$ of men and $20.3 \%$ of the women with surgery performed in 35 patients (7.8\%) and stereotactic body radiation therapy (SBRT) in 48 patients (10.6\%). Chemotherapy was given to 51 patients $(11.2 \%)$ and palliative radiotherapy to 77 (17.0\%). Second-line chemotherapy was given in $4 \%$ and third-line in 1.5\%. Only one patient received
\end{abstract}

Correspondence to: Hirsh Koyi, Department of Respiratory Medicine, Gävle Hospital, S-80187 Gävle, Sweden. Tel: +46 26154327, Cell: +46 703890101, Fax: +46 26157630, e-mail: hirsh.koyi@regiongavleborg.se

Key Words: Non-small cell lung cancer, octogenarians, clinical practice. fourth-line. Male patients who received chemotherapy survived a mean of 281 days and for female patients it was 332 days (not significant). Median overall survival (OS) was 115 days in patients receiving BSC and 362 days in patients given any therapy. Patients who underwent surgery for stage I-II had a median OS of 5.6 years compared to 3.5 years for patients given SBRT. Conclusion: Treatment of NSCLC patients 80 years and older with any modality is feasible with a good PS. Survival is fairly good with surgery or SBRT.

Lung cancer (LC) is one of the most important causes of cancer morbidity and mortality worldwide (1). In Sweden, LC is the number one cause of cancer mortality. Due to a general increase in life expectancy in most countries, the proportion of elderly in the general population is steadily growing, causing new social and health problems. The risk of cancer also increases with age (2); consequently, the number of patients with LC aged 65 years and above is increasing. This trend is expected to continue over the next decades (3) and the proportion of the population aged more than 70 years is expected to double by 2020 (4). In an analysis from the USA, approximately half of lung cancer cases are diagnosed in people aged more than 70 years and around $15 \%$ are diagnosed in patients aged more than 80 years (3).

Patients aged above 80 years are often excluded from clinical trials and it is, therefore, not clear if existing data, including the use of systemic cytotoxic chemotherapy, can be applied for this age group (5-12). Given this background, we examined a large database to determine how elderly patients aged 80 and above have been treated in clinical practice at our Department.

\section{Patients and Methods}

This was a single-centre, retrospective cohort study in all elderly patients (aged $\geq 80$ years) diagnosed at the Department of Respiratory Medicine and Allergy at the Karolinska University Hospital in Solna, 
Table I. Baseline patients' demographics.

\begin{tabular}{|c|c|c|c|}
\hline Patients N (\%) & Male & Female & Total \\
\hline & $216(47.8 \%)$ & $236(52.2 \%)$ & $452(100 \%)$ \\
\hline Age: Mean (Median) Range & $83.8(83.0) 80-96$ & $83.7(83.0) 80-95$ & $83.8(83.0) 80-96$ \\
\hline \multicolumn{4}{|l|}{ Smoking ${ }^{\mathrm{a}}$} \\
\hline Current smoker & $46(21.6 \%)$ & $72(31.3 \%)$ & $118(26.6 \%)$ \\
\hline Former smoker & $148(69.5 \%)$ & $147(46.5 \%)$ & $255(57.6 \%)$ \\
\hline Never smoker & $19(8.9 \%)$ & $51(22.2 \%)$ & $70(15.8 \%)$ \\
\hline \multicolumn{4}{|l|}{ PS (WHO) $)^{b}$} \\
\hline 0 & $17(7.9 \%)$ & $20(8.5 \%)$ & $37(8.2 \%)$ \\
\hline 1 & $77(35-6 \%)$ & $91(38.6 \%)$ & $168(37.2 \%)$ \\
\hline 2 & $57(26.4 \%)$ & $59(25.0 \%)$ & $116(25.6 \%)$ \\
\hline 3 & $57(26.4 \%)$ & $56(23.7 \%)$ & $113(25.0 \%)$ \\
\hline 4 & $8(3.7 \%)$ & $10(4.2 \%)$ & $18(4.0 \%)$ \\
\hline \multicolumn{4}{|l|}{ Tumor stage ${ }^{c}$} \\
\hline Ia & $23(10.6 \%)$ & $37(15.7 \%)$ & $60(13.3 \%)$ \\
\hline $\mathrm{Ib}$ & $38(17.6 \%)$ & $33(14.0 \%)$ & $71(15.7 \%)$ \\
\hline IIa & $1(0.5 \%)$ & $3(1.3 \%)$ & $4(0.9 \%)$ \\
\hline $\mathrm{IIb}$ & $9(4.2 \%)$ & $9(3.8 \%)$ & $18(4.0 \%)$ \\
\hline IIIa & $24(11.1 \%)$ & $19(8.1 \%)$ & $43(9.5 \%)$ \\
\hline IIIb & $64(29.6 \%)$ & $47(20.0 \%)$ & $11(24.6 \%)$ \\
\hline IV & $57(26.4 \%)$ & $87(37.0 \%)$ & $144(31.9 \%)$ \\
\hline
\end{tabular}

${ }^{\mathrm{a}} p<0.001 ;{ }^{\mathrm{b}} p=0.934 ;{ }^{\mathrm{c}} p<0.037$.

Stockholm, from 1st January, 2003 to 31st December, 2010 and followed until June 1st, 2016. Practically all patients with suspected LC are referred to this Department from the Northern Stockholm area. Patients were identified using the Stockholm-Gotland Cancer Registry, which is known for its high level of comprehensive data reporting.

The following variables were included in the retrospective analysis: gender, smoking history, performance status (PS) according to WHO, comorbidities according to Charlson Comorbidity Index (CCI) (13), TNM stages (14), LC type, total numbers of lines of treatment, type of therapy (surgery, chemotherapy, radiation, chemoradiotherapy, etc.) and overall survival (OS). Information about other treatments patients had received, such as second- or third-course treatment, were also collected. Data were extracted by two of the authors from paper charts, electronic medical records and electronic chemotherapy ordering systems.

The study was approved by the Ethics Committee of the Karolinska Institutet 2005/115 and 2015/2:10.

Statistical analysis. Statistics software R (version 3.2.3; R Core Team, www.R-project.org) was used for all study analyses. Patients' characteristics at point of diagnosis were summarized using standard descriptive statistics. Observed frequencies in categorical variables were calculated. Survival time after diagnosis was analyzed using Kaplan-Meier estimates and differences in survival distributions for different patient subgroups were tested using log-rank tests. Differences in categorical variables between subgroups were statistically tested using Fisher's exact test, using Monte Carlo simulation with 20,000 replicates for variables with more than two categories. The significance level was set at 0.05 for all statistical tests. Comorbidities were analyzed according to CCI (13).

\section{Results}

In total, 2,662 patients were newly diagnosed with LC during the period. Of these, $312(11.7 \%)$ had small-cell lung cancer and were excluded, leaving 2,350 patients. Of these 2,350 patients, $452(19.2 \%)$ were aged $\geq 80$ years. Of these 452 patients, $28(6.2 \%)$ were aged $>90$ years.

Of the 452 patients, $216(47.8 \%)$ were men and 236 $(52.2 \%)$ female, with a median age of 83.0 years (range $=80$ 96) (Table I).

Of the male patients, 46 (21.6\%) were smokers, 148 $(69.5 \%)$ ex-smokers and $19(8.9 \%)$ had never smoked; the corresponding figures for female patients were $72(31.3 \%)$, $147(46.5 \%)$ and $51(22.2 \%)$, respectively. The difference in smoking habits between genders was statistically significant, with $77.8 \%$ of the female patients having ever smoked and $91.1 \%$ of the male patients $(p<0.001)$ (Table I).

PS was $0-1$ in 205 patients $(45.4 \%), 2$ in $116(25.6 \%)$ and PS $3-4$ in $131(29.0 \%)$. There were no statistical significant differences between the genders $(p=0.939)$ (Table I).

Stage IIIb-IV was the most common LC stage, seen in 255 patients $(56.5 \%)$, stage IIIa in $43(9.5 \%)$ and stage I-II in 153 $(33.9 \%)$. There was a statistically significant difference in staging between the genders with women having lower stages $(p=0.037)$ (Table I).

Adenocarcinoma was the most prevalent histology type and occurred in 206 (45.6\%) patients; squamous cell carcinoma was 
Table II. Type of lung cancer.

\begin{tabular}{lcrr}
\hline Histopathologya & Male & Female & Total \\
\hline Adenocarcinoma & $86(39.8 \%)$ & $120(50.8 \%)$ & $206(45.6 \%)$ \\
Squamous cell carcinoma & $50(23.1 \%)$ & $32(13.6 \%)$ & $82(18.1 \%)$ \\
Low-differentiated cell carcinoma & $26(12.0 \%)$ & $22(9.3 \%)$ & $48(10.6 \%)$ \\
Lung cancer - clinical diagnosis & $50(23.1 \%)$ & $55(23.3 \%)$ & $105(23.2 \%)$ \\
Large cell carcinoma & $3(1.4 \%)$ & $2(0.8 \%)$ & $5(1.1 \%)$ \\
Adenosquamous cell carcinoma & $0(0.0 \%)$ & $3(1.3 \%)$ & $2(0.4 \%)$ \\
Bronchoalevolar cell carcinoma & $1(0.5 \%)$ & $4(0.9 \%)$ & \\
\hline
\end{tabular}

${ }^{\mathrm{a}} p<0.041$.

Table III. Treatment.

\begin{tabular}{lccc}
\hline Treatment & Men & Women & Total \\
\hline Best supportive care & $93(43.1 \%)$ & $116(49.2 \%)$ & $209(46.2 \%)$ \\
Potentially curative therapies: & & & \\
Surgery & $13(6.1 \%)$ & $22(9.3 \%)$ & $35(7.8 \%)$ \\
thereof neoadjuvant chemotherapy & $1(0.5 \%)$ & $2(0.8 \%)$ & $3(0.7 \%)$ \\
$\quad$ thereof adjuvant chemotherapy & $1(0.5 \%)$ & 0 & $1(0.2 \%)$ \\
SBRT & $23(10.6 \%)$ & $25(10.6)$ & $48(10.6)$ \\
Concomitant chemo-radiotherapy & $2(0.9 \%)$ & $1(0.4 \%)$ & $3(0.7 \%)$ \\
TOTAL & $36(16.5 \%)$ & $46(20.3 \%)$ & $82(18.7 \%)$ \\
Palliative treatments: & & & \\
Chemotherapy & $26(11.3 \%)$ & $25(10.6 \%)$ & $51(11.2 \%)$ \\
Palliative radiation & $42(19.4 \%)$ & $35(14.8 \%)$ & $77(17.0 \%)$ \\
EGFR-TKI & $4(1.9 \%)$ & $4(1.7 \%)$ & $8(1.8 \%)$ \\
TOTAL & $72(32.6)$ & $64(27.1 \%)$ & $136(30.0 \%)$ \\
\hline
\end{tabular}

EGFR-TKI, Epidermal growth factor inhibitor-tyrosine kinase inhibitor; SBRT, stereotactic body radiation therapy.

second most prevalent and occurred in $82(18.1 \%)$ patients. Low differentiated NSCLC occurred in $48(10.6 \%)$ patients. A histological diagnosis was not available in 105 (23.2\%) patients for ethical reasons. There was a statistically significant gender difference in histology types with adenocarcinoma more common in women $(p<0.0412)$ (Table II).

Best supportive care (BSC) only was given to 209 patients $(46.2 \%)$. Potentially curative therapy was administered to $16.5 \%$ of the male patients and $20.3 \%$ of the female patients, with surgery performed in 13 male and 22 female, in all 35 patients $(7.8 \%)$, and stereotactic body radiation therapy (SBRT) in 23 men and 25 women, in all 48 patients (10.6\%) (Table III).

Chemotherapy was given to 51 patients $(11.2 \%)$ and palliative radiotherapy to $77(17.0 \%)$ (Table III). Of the patients who received chemotherapy, $60.8 \%$ were given carboplatin and gemcitabine, $7.8 \%$ carboplatin and vinorelbine, $11.8 \%$ gemcitabine alone and $15.7 \%$ vinorelbine alone. Most patients (47\%) received at least four cycles and another $6 \%$ patients received three cycles. Only $4 \%$ of the treated patients received second-line and $1.5 \%$ third-line chemotherapy. Only one patient received fourth-line. Oral targeted therapy was given only to $8(1.8 \%)$ patients in our study. Chemotherapy was stopped in $12.2 \%$ due to hematological toxicities, in $18.4 \%$ because of nonhematologic toxicities and $4.1 \%$ due to progressive disease.

There was no statistical significant difference in treatment between the genders $(p=0.144)$.

The median survival time for the male patients was 208 days $(95 \%$ confidence interval $(C I)=149-257$ and for the female patients this figure was 256 days (95\% CI=219-332), based on 216 male patients and 236 female patients. There was, thus, a statistically significant difference in the survival between the genders $(p=0.018)$ (Figure 1). While the median survival for the male patients receiving only BSC was 80 days, 95\% CI=66-146 $(\mathrm{n}=93)$ for the female patients it was 130 days, $95 \% \mathrm{CI}=106-171(\mathrm{n}=116)(p=0.018)$. 


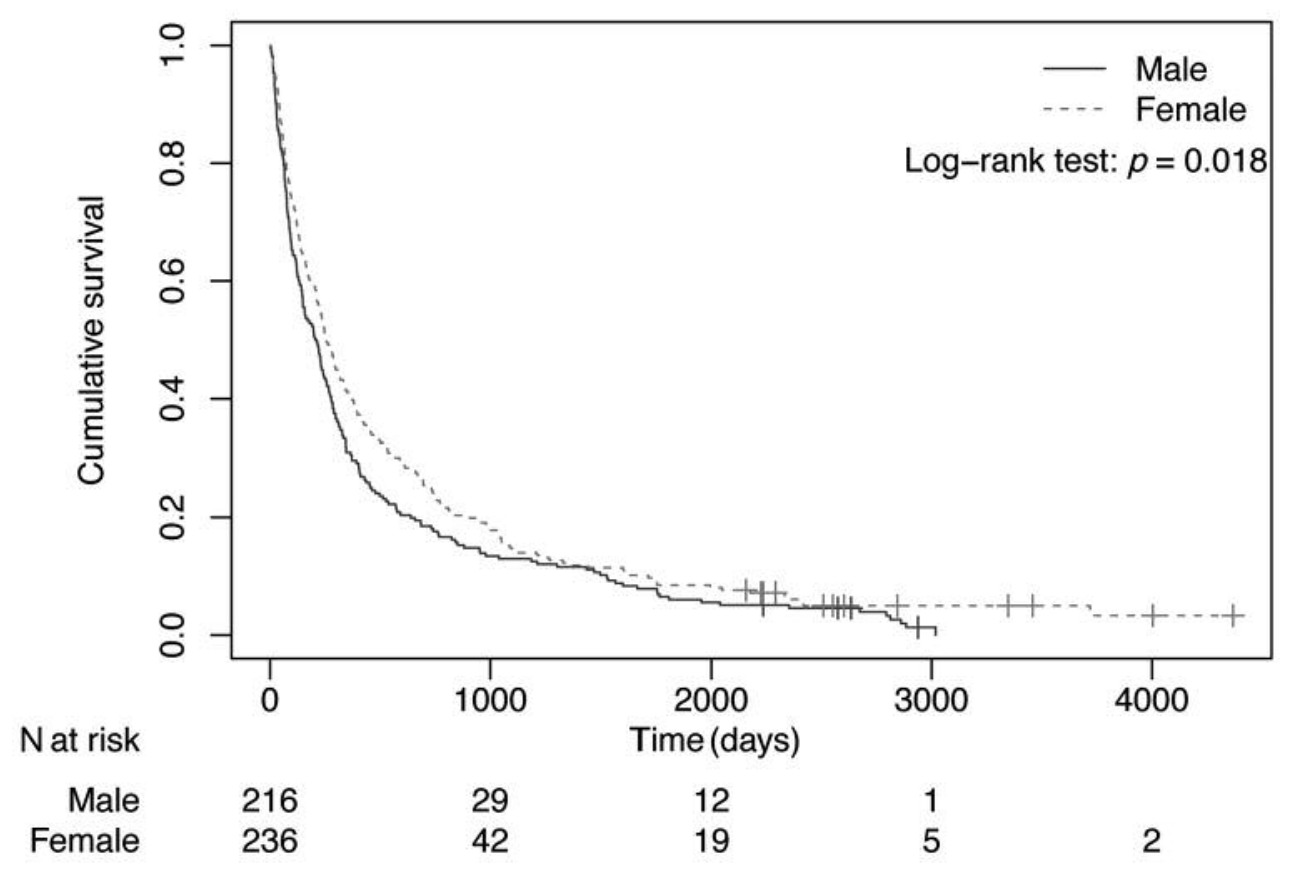

Figure 1. Kaplan-Meier estimates of overall survival between the genders.

The median survival time in patients who underwent surgery for stage I-II was 5.6 years, 95\% CI=3.93-8.26 $(\mathrm{n}=31)$ and for SBRT patients it was 3.5 years, $95 \%$ $\mathrm{CI}=2.33-4,40(\mathrm{n}=48)$ (Figure 2).

For male patients who received chemotherapy the median survival time was 281 days, $95 \% \mathrm{CI}=204-497(\mathrm{n}=26)$ and for the female patients it was 332 days, $95 \% \mathrm{CI}=255-605(\mathrm{n}=25)$. The difference was not statistically significant $(p=0.83$ ) (Figure 3 ).

The median survival time in male patients receiving palliation radiotherapy was 238 days, 95\% CI=179-344 $(\mathrm{n}=42)$ and for the female patients it was 246 days, $95 \%$ $\mathrm{CI}=174-357(\mathrm{n}=35)(p=0.53)$.

\section{Discussion}

This is, to our knowledge, the first study to comprehensively evaluate outcomes of such a large number of octogenarians with NSCLC in real-life, clinical practice in Europe and Western countries. We found that $46.2 \%$ of the patients received BSC only, which is similar to two Japanese studies $(15,16)$ but in another only $11 \%$ were given BSC alone (17). Multiple factors influence the choice of treatment, if any: PS, comorbidities, physician attitudes and not the least patient preferences. In our study we found that the most common documented reason for not receiving therapy was PS and comorbidities.

As mentioned, clinical information regarding use of chemotherapy in patients aged 80 and above with advanced
NSCLC is not readily available because such patients are not usually included in clinical trials or retrospective analyses (5-12). One of the many reasons chemotherapy is less often offered to patients over 80 is the perceived increase in toxicity risk (18). In two recently published papers very few patients received chemotherapy ( 6 and $4 \%$, respectively) (1920 ). In our study the number was higher, $11.2 \%$, probably mainly explained by the fact that our patients had better PS and there were relatively few complications.

The median OS in the present study was 9.5 months for patients who received chemotherapy, which is similar to the literature $(16,19)$.

It is evident from the literature that many elderly patients have been denied potentially beneficial treatment solely because of chronological age $(3,21-23)$. On the contrary, the benefit of standard therapy (surgery, radiation, chemoradiation and chemotherapy) is well-demonstrated in the elderly population in general and is comparable to the benefit obtained by younger patients (25-30).

During the study time, treatment modalities were changing. Epidermal growth factor inhibitor-tyrosine kinase inhibitor (EGFR-TKI) treatment, for example, was not generally available until the last year of the study and is today much more often used. SBRT is another treatment modality the use of which is rapidly increasing, while immune therapies and other modalities will most probably completely revolutionize the future care of lung cancer patients. 


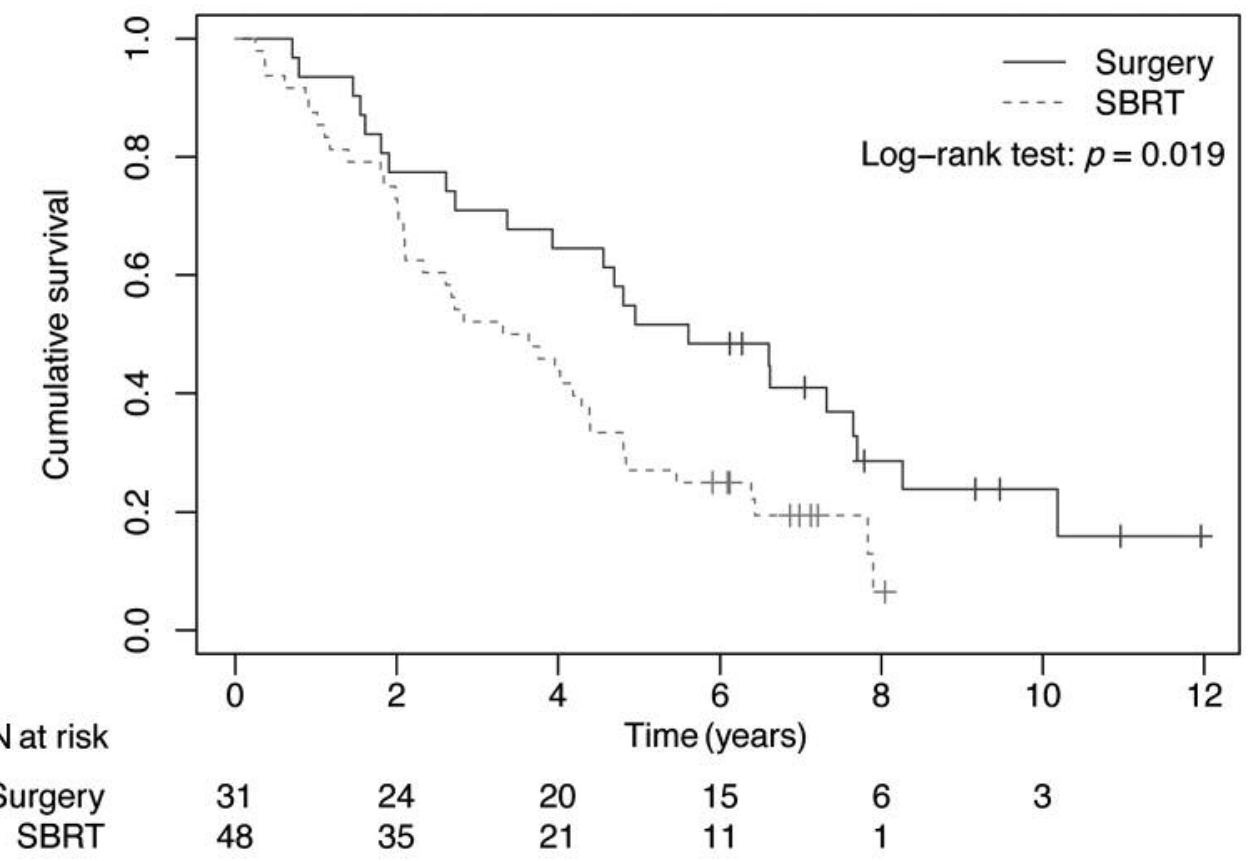

Figure 2. Kaplan-Meier estimates of overall survival between patients who underwent surgery or stereotactic body radiation therapy (SBRT).

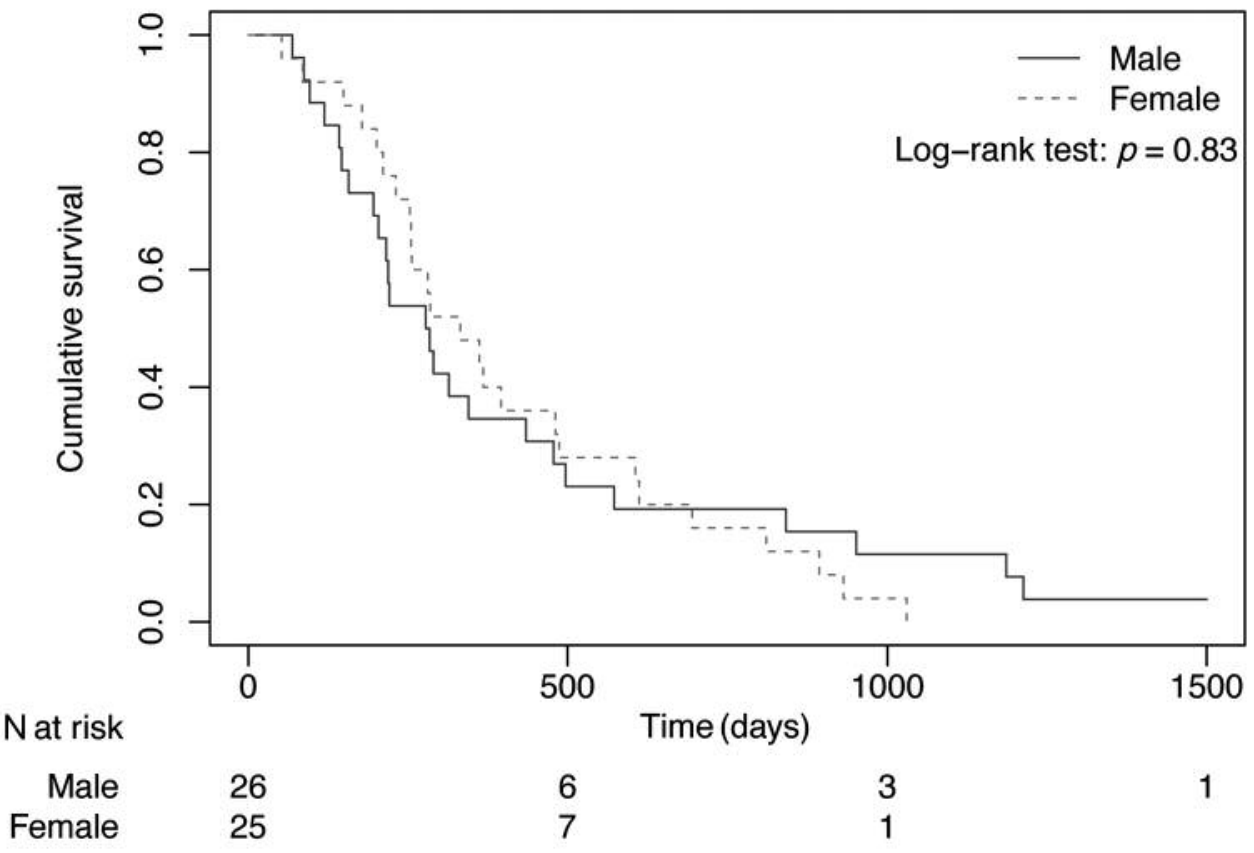

Figure 3. Kaplan-Meier estimates of overall survival between the genders given chemotherapy.

Our study suffers from limitations imposed by its retrospective nature; however, we believe that it is important to report clinical features and outcomes of lung cancer in the very elderly. The 80 year and above age group is rapidly increasing in size. This study confirms that treatment of NSCLC patients with a good PS 80 years and older with any modality is feasible as survival is fairly good with both surgery and SBRT. It is essential that the very elderly can also benefit from the rapid advances that now occur in the field. 
In order to improve the outcome, detection of early stage lung cancer and thorough pretreatment evaluation is essential even for this age group of patients.

\section{References}

1 Ferlay J, Steliarova-Foucher E, Lortet-Tieulent J, Rosso S, Coebergh JWW, Comber H, Forman D and Bray F: Cancer incidence and mortality patterns in Europe: estimates for 40 countries in 2012. Eur J Cancer 49: 1374-1403, 2013.

2 Mistry M, Parkin DM, Ahmad AS and Sasieni P: Cancer incidence in the United Kingdom: projections to the year 2030. Br J Cancer 5: 1795-1803, 2011.

3 Owonikoko TK, Ragin CC, Belani CP, Oton AB, Gooding WE, Taioli $\mathrm{E}$ and Ramalingam SS: Lung cancer in elderly patients: an analysis of the surveillance, epidemiology, and end results database. J Clinical Oncology 25: 5570-5577, 2007.

4 Hoffe S and Balducci L: Cancer and age: General considerations. Clin Geriatr Med 28: 1-18, 2007.

5 Hesketh PJ, Lilenbaum RC, Chansky K, Dowlati A, Graham P, Chapman RA, Crowley JJ and Gandara DR: Chemotherapy in patients $>80$ with advanced non-small cell lung cancer: Combined results from SWOG 0027 and LUN 6. J Thorac Oncol 2: 494-498, 2007.

6 Lewis JH, Kilgore ML, Goldman DP, Trimble EL, Kaplan R, Montello MJ, Housman MG and Escarce JJ: Participation of patients 65 years of age or older in cancer clinical trials. J Clin Oncol 21: 1383-1389, 2003.

7 Hutchins LF, Unger JM, Crowley JJ, Coltman CA and Albain KS: Underrepresentation of patients 65 years of age or older in cancer-treatment trials. N Engl J Med 341: 2061-2067, 1999.

8 Murthy VH, Krumholz HM and Gross CP: Participation in cancer clinical trials: race-, sex-, and age-based disparities. JAMA 29: 2720-2726, 2004.

9 Balducci L and Extermann M: Management of cancer in the older person: A practical approach. Oncologist 5: 224-237, 2000.

10 Davidoff AJ, Tang M, Seal B and Edelman MJ: Chemotherapy and survival benefit in elderly patients with advanced non-small cell lung cancer. J Clin Oncol 28: 2191-2197, 2010.

11 Schiller JH, Harrington D, Belani CP, Langer C, Sandler A, Krook J, Zhu J and Johnson DH: Comparison of four chemotherapy regimens for advanced non-small cell lung cancer. N Engl J Med 346: 92-98, 2002.

12 Gridelli C, Perrone F, Gallo C, Cigolari S, Rossi A, Piantedosi F, Barbera S, Ferraù F, Piazza E, Rosetti F, Clerici M, Bertetto O, Robbiati SF, Frontini L, Sacco C, Castiglione F, Favaretto A, Novello S, Migliorino MR, Gasparini G, Galetta D, Iaffaioli RV and Gebbia V: Chemotherapy for elderly patients with advanced non-small cell lung cancer: The Multicenter Italian Lung Cancer in the Elderly Study (MILES) phase III randomized trial. J Natl Cancer Inst 95: 362-372, 2003.

13 Charlson ME, Pompei P, Ales KL and MacKenzie R: A new method of classifying prognostic comorbidity in longitudinal studies: Development and validation. J Chron Dis 40: 373-383, 1987.

14 Mountain CF: A new international staging system for lung cancer. Chest 89: 225-233, 1986.

15 Kurishima K, Satoh H, Ishikawa H, Yamashita YT, Ohtsuka M and Sekizaw K: Lung cancer in the octogenarian. Gerontology 47: 158-160, 2001.
16 Kawaguchi T, Tamiya A, Tamura A, Arao M, Saito R, Matsumura A, Ou S HI and Tamura T: Chemotherapy is beneficial for elderly patients with advanced non-small cell lung cancer: Analysis of patients aged 70-74, 75-79, and 80 or older in Japan. Clin Lung Cancer 16: 442-447, 2012.

17 Oxnard GR, Fidias P, Muzikansky A and Sequist LV: Non-small cell lung cancer in octogenarians: Treatment practices and preferences. J Thorac Oncol 2: 1029-1035, 2007.

18 Kornblith AB, Kemeny M, Peterson BL, Wheeler J, Crawford J, Bartlett N, Fleming G, Graziano S, Muss H and Cohen HJ: Survey of oncologists' perceptions of barriers to accrual of older patients with breast carcinoma to clinical trials. Cancer 9: 989-996, 2002.

19 Howell M, Chiramel J, Flaum N, Lewis A, Summers Y, Taylora PD, Chittalia A, Sheikh $\mathrm{H}$ and Blackhalla F: Outcomes of octogenarian ( $\geq 80$ yo) patients with advanced non-small cell lung cancer (NSCLC): A single institution experience at the Christie Hospital. Lung Cancer 91: 75-76, 2016.

20 Baimatova I, Smith C, Beckert L and Singh H: Treatment of octogenarians with lung cancer: A single centre audit of treatments and outcomes. NZMJ 128: 29-34, 2015.

21 Taylor KM, Feldstein ML, Skeel RT, Pandya KJ, Ng P and Carbone PP: Fundamental dilemmas of the randomized clinical trial process: Results of a survey of the 1737 Eastern Cooperative Oncology Group investigators. J Clin Oncol 12: 1796-1805, 1994.

$22 \mathrm{Ng} \mathrm{R}$, de Boer R and Green MD: Under treatment of elderly patients with non-small cell lung cancer. Clin Lung Cancer 7: 168-174, 2005.

23 Sawada S, Komori E, Nogami N, Bessho A, Segawa Y, Shinkai T, Nakata M and Yamashita M: Advanced age is not correlated with either short-term or long-term postoperative results in lung cancer patients in good clinical condition. Chest 128: 1557-1563, 2005.

24 Cerfolio RJ and Bryant AS: Survival and outcomes of pulmonary resection for non-small cell lung cancer in the elderly: A nested case-control study. Ann Thorac Surg 82: 424-430, 2006.

25 Hurria A and Kris MG: Management of lung cancer in older adults. CA Cancer J Clin 53: 325-341, 2003.

26 The Elderly Lung Cancer Vinorelbine Italian Study Group: Effects of vinorelbine on quality of life and survival of elderly patients with advanced non-small-cell lung cancer. J Natl Cancer Inst 91: 66-72, 1999.

27 Costa GJ, Fernandes AL, Pereira JR, Curtis JR and Santoro IL: Survival rates and tolerability of platinum-based chemotherapy regimens for elderly patients with non-small-cell lung cancer (NSCLC). Lung Cancer 53: 171-176, 2006.

28 Rocha Lima CM, Herndon JE and Kosty M, Clamon G and Green MR: Therapy choices among older patients with lung carcinoma: An evaluation of two trials of the Cancer and Leukemia Group B. Cancer 94: 181-187, 2002.

29 Langer CJ, Manola J, Bernardo P, Kugler JW, Bonomi P, Cella D and Johnson DH: Cisplatin-based therapy for elderly patients with advanced non-small-cell lung cancer: Implications of Eastern Cooperative Oncology Group 5592, a randomized trial. J Natl Cancer Inst 94: 173-181, 2002.

Received August 10, 2016

Revised September 2, 2016

Accepted September 6, 2016 